\title{
Social and Cultural Integration as a Way of Resolving the Identities Conflicts in the Modern Russia: A Regional Aspect
}

\author{
Maxim Popov \\ Doctor of philosophical sciences, Professor, Chair of Social Philosophy and Ethnology \\ North-Caucasian Federal University; maximus.popov@gmail.com
}

\section{Doi:10.5901/mjss.2015.v6n6s5p325}

\section{Abstract}

\begin{abstract}
The goal of the research is to analyze the social and cultural integration as a tool for resolving the identities conflicts in the modern Russia. The methodology of research includes the systemic, social and philosophical analysis of social and cultural integration as a way for settling the identities conflicts in the North Caucasus. As a result of the study the author comes to the fact that a theoretical synthesis of conflictological paradigm and neofunctionalism is essential. In the paper, it is concluded that the modern conflicts resolution theory focuses its attention on the capacity of social and cultural integration to transform the destructive identities conflicts into constructive conflicts of interests. The author considers the structural factors of regional identities conflicts escalation and emphasizes the destabilizing role of ethnicity politicization. As the conditions of growth for the ethnic tension in the North Caucasus and its transformation into destructive identities conflicts, the author singles out the social inequalities, civic identity crisis, and ethnic mobilization. Proceeding from the analysis conducted, the author identifies the main factor of regional identities conflicts escalation: the controversy between systemic modernization and social disintegration. Finally, the conclusion is drawn about that the conflict resolution strategy for the Russian society has to be built on the principles of civic solidarity and social and cultural integration but not on the assimilation policy and suppression of ethnic distinctions.
\end{abstract}

Keywords: social and cultural integration, identities conflicts, conflict resolution, Russian society, the North Caucasus.

\section{Introduction}

The problem of analyzing the social and cultural integration as a way of de-escalation and settlement of weighty identities conflicts theoretically is associated with solving the following research tasks: 1) the methodological synthesis of social conflict theories and neofunctionalist paradigm; 2) finding the structural causes and factors of growth of ethnic tension in the North Caucasian region; 3) conceptualizing the social and cultural integration and representing it as a tool for resolving the ethnic controversies in the North Caucasus.

The specific character of identities conflicts as new challenges to the Russian society integration consists in their taking place against the background of ethnic tension escalation and as a result of clash of competing values. The notion of value clash makes the identities conflict concept more precise by emphasizing the systemogenetic character of this explanatory model. The identities conflicts are a consequence of social inequalities growth and ethnicity politicization which threaten the integration and modernization processes in transforming Russia and in the North Caucasian region. The identities conflicts and social disintegration aggravate the polarization of the Russian society, generate apathy and passivity of the population while pushing the carriers of radical ideologies toward illegitimate forms of protest and political extremism.

The social globalization is characterized by the trend to increased ethnic contacts, which blurs the cultural and political boundaries. Systemic stability and integrity of polyethnic democracies can be built on the basis of macro-social solidarity and civic integration. In connection to this, the comprehensive analysis of social and cultural integration that is treated as a multi-dimensional process of value consolidation owing to which individuals and ethno-social groups achieve a high level of compatibility with the metacultural environment forming the integration identity gains a priority meaning.

The problem of social and cultural integration of regional communities against the changing conditions of globalization is one of the relevant in theoretical, methodological and practical aspects. This is due to the fundamental status of the integration problems in the contemporary social sciences as well as to the search for new integration resources and mechanisms for overcoming the social and cultural conflicts.

Post-Soviet transformations conditioned the crisis of values and institutions of social consolidation in the North Caucasus. The relevance of studying the anti-conflictogenic potential of social and cultural integration in the North 
Caucasian region is caused by the necessity to elaborate the new metaethnic models of consolidation forming the integration identity and supporting the cross-cultural dialogue and interethnic cooperation.

In the North Caucasus, social and cultural integration as a process of supporting and promoting the civic values, identities, institutions and enabling all social subjects to participate in political life on the basis of principles of justice and equal rights becomes the major method of resolving the ethnic identities conflicts. Integration eliminates the process of mechanic consolidation based on the force of assimilatory compulsion and suppression of cultural distinctions in a repressive attempt to impose a unified identity.

\section{Methodology, Methods and Stages of the Research}

The methodological basis of our research is systemic analysis of social and cultural integration as a mechanism of resolving the identities conflicts. Systemic methodology allows viewing the social and cultural integration as an integral phenomenon conditioned by a diversity of social, historical, ethnic, cultural and political factors.

At the stage of studying the structural causes of ethnic tension escalation in the North Caucasus, an important methodological basis is the concept of "identities conflicts" by J. Burton and J. Rothman. It allows determining the identities conflicts as social ones by their form (occurring between social subjects of various levels) and as value conflicts by their content, relying on cultural distinctions.

At the stage of studying the mechanisms of social and cultural integration in resolving the ethnic conflicts, the neofunctionalist and conflictological approaches are applied. The conflicts resolution theory focuses its attention on the capacity of social and cultural integration to transform the destructive identities conflicts into constructive conflicts of interests. Social and cultural integration is interpreted as a method of resolving the value controversies on the basis of making the ethnicity non-political while constituting the civic identity.

\section{Results and Discussion}

The theoretical tradition of studying the social and cultural integration is associated with the conceptual confrontment of the theories of conflict, multiculturalism, liberal and egalitarian methodology. The controversy consists in treating the essence of an ethnic conflict and reasonability of rights for ethnic minorities in pluralist societies.

With regard to this, the conflictologists rely on analyzing the conflictogenic nature of ethnicity. The multiculturalists proceed from the normalization of ascriptive status of identification with ethno-cultural and religious traditions. Meanwhile, the representatives of egalitarian and neofunctionalist paradigm interpret the rights of minorities from the standpoint of equal opportunities and the structural principle of civic integration.

The necessity of promoting the social and cultural integration in the North Caucasus is due to instrumental causes: from the ethic viewpoint, the creation of an integrated "society for everyone" is self-evident societal goal; the structural causes of supporting the integration are associated with economic, social, ethnic distinctions that reduce mobility, which in its turn leads to social fragmentation and produces a negative effect on the modernization process and prevention of ethnic conflicts in their most destructive form - the conflicts of identities.

Social and cultural integration as a social construct depends on three different yet interrelated process which form the integration civic identity in the systemic unity, in particular:

1. Acknowledgement of ethnic identities pluralism for promoting the social solidarity within the legal space.

2. Political representation of ethnic communities for granting a guarantee of the interests, identities and values of various groups being taken into account when state decisions are made and resources are allocated.

3. Redistribution of economic and political resources between various social subjects for preventing the inequalities, disproportions and fragmentation on the basis of economic status, ethnic and religious identity.

These grounds and principles of social and cultural integration in the process of resolving the identities conflicts in the North Caucasus are based on the conceptual models of pluralism, justice, human rights, social inclusion, equal opportunities, and solidarity. The combination of concepts of individual freedom and group loyalty as counter-narratives to forced assimilation can be viewed as movement toward pluralism and respect for cultural distinctions at both individual and collective levels. When analyzing the status of identities in the dynamics of conflicts, the authors point at the association of group identities with the primordial and pre-modern idea of society, which brings us back to studying the closed groups where individualism plays no noticeable ideological role. Today such societies can function in the globalized world by means of keeping their own culture on the basis of collective values; within the groups, the group identification can be correlated to their genuine values, traditions or religious texts. When we are dealing with a group clash during mediation, turning to individual interests cannot smooth out the gap emerging due to the conflict. Any 
attempts to manipulate the groups can bring about the intensification of identities conflicts (Rothman \& Alberstein, 2013).

Social justice, creation of the society for everyone is an overarching goal and a crucial structural element of social and cultural integration of the North Caucasus. Social justice belongs to societal principles, values and institutions which enable each person to obtain a fair share of benefit for a fair share of responsibility within the joint living in the society. The social justice concepts determine the civic society as the most desirable and attainable on condition that the rights and responsibilities are distributed in line with the agreed equality principles; this is a society where all people can take part in social, economical and political life on the basis of equal rights and opportunities, justice and merit.

Social and cultural integration reduces the ethnic tension, which is associated with a high level of solidarity and security, reduction of social problems interpreting by means of creating negative ethnic stereotypes of "others" as "cultural enemies". In the North Caucasian region, the main objective of integration is to rationalize the controversies in the process of transformation of conflictogenic hierarchical system of ethnic relationships. Each ethnic conflict has its own unique characteristics and some of these elements will be more noticeable than the others in various contexts. However, they are all common denominators of the ethnic conflict genesis. The primordialist approach helps explain the role of conflict potential of an ethnic identity. The concepts of political entrepreneurs and resource competition approaches explain how the institutional and political factors interact with ethnic emotions. The diverse ethnic communities have various extents of the conflict potential. The ethnic emotions rooted in memories of historical offences underlie the potential conflicts of identities.

The ethnicity embodies in itself an element of a powerful emotional tension which can be reactivated if the groups realize a threat to their own interests. This results in ethnification, ethnic intolerance, competition and ultimately - in a violent ethnic conflict. At the macro-social level, the social and cultural integration forms the rational and communicative mechanisms consolidating the civic society on the basis of tolerance and metaethnic solidarity.

In the North Caucasus, ethnicity politicization as a factor of ethno-social tension directly depends on the acuteness of feeling the threats to group security. The conflicts of identities are dangerous because in their genesis and dynamics the ethnic stereotypes and social dissatisfaction are highly likely to be politicized. The effect of attitudes to violence consists in focusing the socially aggressive potential in the point of ethnic irreconcilability.

The extent of violence in identities conflicts is determined by the acuteness of perceiving the threats to group security, the intensity of social dissatisfaction, and the scale of institutional support, which jointly are the conditions of open confrontation. In the North Caucasian region, the negative ethnic stereotypes in interpreting the threats to group security and generated by value and structural controversies act as a source of in-depth identities conflicts. The modernization transformations change the hierarchy of collective identities in the opposition "us - them" by means of making the citizenship and equality universal; the value and structural change of group identities, however, become the factors of disintegration and regionalization.

The term "identities conflicts" was coined in the works of J. Burton and J. Rothman in the 1990s. J. Burton views the collective identity as one of the basic needs of a human; with regard to this, a threat to the identity is perceived by the group as one of the main threats to security. Moreover, J. Burton singles out two needs as the key ones: the need of identity and the need of security (Burton, 1990). According to J. Rothman, the most important attributes of identities conflicts are their irrationality, deep subjective character and uncontrollability (Rothman, 1997).

The motives of participation of ethnic groups in identities conflicts will influence the prospects of their outcome; people will hardly ever risk their lives consciously for mere satisfaction of their material interests. In the conflicts of identities, participation of parties has a pronounced character of willingness to make sacrifices: readiness to sacrifice for their value ideals is emotionally felt and realized by the participants of the conflicts. The escalation of ethnic tension also takes place when a group perceives itself as a "victim" of value aspirations from the part of "other" groups.

From the point of its emergence, the "conflict resolution" paradigm argues that manifestation of a conflict does not always indicate its true essence. The approach of conflict resolution demands to avoid the superficial analysis of open antagonistic claims which are the top of the conflict iceberg but rather to focus on its concealed in-depth layer. The analysis of the "hidden meaning" of the conflict interaction occupies the central place in the contemporary theory of conflict and in development of constructive methods for transforming, settling, controlling and resolving the conflicts. Without actualizing the problem of either the economic interests or biological needs determining the concealed layer of the conflict, all conflict resolution schools maintain that working with identity, the in-depth level of the conflict, becomes more fruitful and constructive if the main controversy having generated it is analyzed.

In the North Caucasus, the technologies of settlement which recommend isolating the identity from the concealed controversy and the conflict situation are an example of conflictological management capable of aggravating but not resolving the ethnic controversy. When a realistic conflict touches on resources or conscious clearly defined goals, the traditional technologies can be a useful reference point in the conflict resolution process. However, as the in-depth 
subjective and emotional problems get involved into the conflicts, such as maintaining the group solidarity and security, it seems impossible to separate the identity from the conflict problem because collective identities of the conflict participants are under threat, at least, this is how the identity conflict parties interpret their genesis. When resolving conflicts of identities, it makes no sense to apply the control methods using the structural separation of various conflict components: an attempt to separate emotions, values, identities from the essence of controversy can only aggravate the ethnic conflict and to give a destructive character to the forms of manifestation thereof.

J. Burton's conflicts resolution theory suggests taking into account the basic human needs that differ from the interests and include the necessity of group security and acknowledgement of the unique identity and using them in anticonflictogenic management during the identity conflict resolution process. The main goal for the identity conflict resolution has to be elimination of moral and psychological threats, tension and disappointments in basic needs and not only satisfaction of the material interests. J. Rothman considers the collective identities as self-perceptions filled with a cultural formula. The cultural formula is based on the inner needs and preferences, group characteristics and collective values. In identities conflicts, it can be personal, group or intergroup one yet the identity is always the source of controversy and conflict catalyst. The parties can perceive themselves as personal maximizers while protecting the individualistic values; they can be groups and feel as a part of a collective unity; they can feel as carriers of multiple cultural identities and enter the conflicts at the intergroup level. All these perceptions are generated by the cultural formula - identity. The identity becomes an ideological basis of the conflict participants which is filled with personal, group and intergroup emotions, values and meanings (Rothman \& Alberstein, 2013).

The analysis of relation between the ethnic tension and identity at the regional level leads us to the idea of destructive effect of intrasystem controversies conditioned by social fragmentation and disintegration, dissatisfaction in the basic needs of equality, justice, and security.

In the empirical study of the ethno-confessional relationships development prospects in the North Caucasus, it is pointed out that interethnic relationships in the region can be characterized as stably tense ones. Alongside with that, neither the former nor the latter are viewed as the acutest problems and rank 11 and 15, respectively, out of 16 suggested in the social problems topicality rating. This result proved to be slightly unexpected, given the character of the place occupied by the ethno-national problems range in the social and political discourse in the region. According to the respondents, the problems which are common for the entire country are the most relevant: corruption and bribery $(48,5 \%)$, prices and taxes growth and inflation (46,5\%), unemployment $(38,6 \%)$, the rise in crime $(34,9 \%)$; housing problem and the communal service problems $(32,8 \%)$. Although the respondents have estimated the probability of interethnic conflicts as average, in conditions of a stable tension any conflict regardless of its true causes can quickly turn into an interethnic one. For such circumstances, perceiving the actions of people of other nationalities as a potential threat to one's own nationality security is characteristic. The situation that has formed creates favorable conditions for ethno-conflict mobilization - quick uniting of people according to their national sign for participating in the conflict actions. The high tension in interethnic relationships is the main reason why local conflicts having an interethnic component keep to break out within the Stavropol territory (Avksentiev \& Shul'ga, 2013).

Alongside with the pronounced social and economic factors of ethnic tension escalation, the processes of traditionalization and regionalization of the North Caucasus also do not allow overcoming the in-depth value controversies. Remaining unresolved, the regional ethnic conflicts which began as the conflicts of interests turn into identities conflicts generating open violence.

In the North Caucasus, radical ethno-nationalism which initiates the conflicts of identities gives evidence about the institutional degradation of civic culture and destabilization of the regional democratic processes. The civic responsibility is changed to ethnicity mobilization; and the religious fundamentalism becomes the most important tool of conflict activity. Traditionalization and regionalization of the North Caucasus in the conditions of lingering identities conflicts do not allow ensuring a stable formation of the integration identity. Regional conflicts which began as the conflicts of interests turn into identities conflicts generating violence, the likelihood of overcoming which is reducing considerably.

The North Caucasian region is characterized both by realistic and non-realistic conflicts, however, with the identities conflicts dominating and overflowing into the violent ones. The conflicts of identities in the North Caucasus are characterized by traditional and affective type of social interactions as well as by the absence of real subject matter, which makes these conflicts emotionally loaded and difficult to resolve. In the identities conflicts, it is orientation to destruction that becomes the strategy of opposing parties. The realistic conflicts (conflicts of interests) develop in a less destructive manner and are easier to settle. Non-realistic conflicts (conflicts of identities) are devoid of rationalized subjective claims. They emerge as the outcome of a in-depth value crisis and as a result of excess tension.

The escalation of social frustration brings about the destruction of systemic integrity of the North Caucasian society. The tension accompanying the emergence of a conflict situation acts as the stage determining further unfolding 
of the conflict either in the direction of its turning into a positive conflict - realistic, rational, constructive one; or to a negative conflict - the irrational, destructive conflict of identities which in this case includes elements of confrontation, violence, compulsion and suppression.

Violence in the regional conflicts is determined by the scale and intensity of social dissatisfaction which acts as a necessary condition for turning to open violence. The acuteness of the identities conflicts is manifested in irrational and aggressive character of parties' confrontation, their orientation to struggle "to the bitter end". The following factors make a conflict situation acute and intractable: 1) identities conflicts touch on existentially important values; 2) the participants are involved into the conflict emotionally; 3 ) identities conflicts cease to be a means of overcoming the frustration but become a goal in itself. The irrational stereotypes in perception of "other" cultures (the negative interpretations of cultural distinctions) play the key part in initiating the conflicts of identities.

The specific character of identities conflicts in the North Caucasus is due to acute controversy between the static (traditionalization) and dynamic (modernization) social systems and it consists in the political mobilization of ethnicity. The ethnic stereotypes as a factor of identities conflicts become the source of intolerance and ethno-nationalism formation.

\section{Conclusion}

It is social inequalities, demodernization and economic polarization that act as the structural factors determining the acuteness of ethnic tension and, consequently, the escalation of identities conflict in the North Caucasus. The source of identities conflict in the region is the controversy between the systemic modernization and social disintegration. Cultural isolationism and political regionalization in the North Caucasus are acquiring a pronounced conflictogenic character.

The social and cultural factors of escalation of regional identities conflicts are the growth of unemployment, low life level, low education level, poor tolerance, adherence to ethnic clan system, desecularisation, and religious fundamentalism.

The specific character of identities conflicts in the North Caucasus is due to an acute controversy between the static (traditionalization) and dynamic (modernization) types of social reproduction and it consists in political mobilization of ethnic and religious identities. The systemic determinants of identities conflicts are ethnicity gaining political aspect, social inequalities, polarization of socium and they remain the main causes of destructive impact on the North Caucasus integration. In these conditions, modernization processes progress in an asynchronous manner, which aggravates the regional isolationism and forms new conflictogenic identities.

The anti-conflictogenic potential of the North Caucasus ethnic communities' integration consists in making the social and political status of co-citizenship relevant and in ensuring a fair access to the social and economic sphere. In this case, the social, cultural and civic integration is perceived by an ethnic community as a safe identification resource and not as an obstacle the restrictions of which they have to get rid of.

The following aspects have to be borne in mind when discussing the anti-conflictogenic and consolidation mechanisms of social and cultural integration in the North Caucasus. First, social and cultural integration is a civilized macro-social project the content of which is to a great extent determined by the problems of ensuring the social security and by the polyethnic configuration of the Russian society. Second, the development of the North Caucasian region after armed ethnic conflicts termination demonstrates that it is inadmissible and impossible to orient to political isolationism and cultural exceptionality of this or that ethnic and social system.

The integration objectives of ensuring the social security and resolving the ethnic controversies in their most destructive form, identities conflicts, have a systemic all-Russian character. De-escalation of ethnic tension during implementation of the regional security policy has to be carried out on the basis of integration identity as a tool for overcoming the value and identification conflicts.

In the North Caucasus, integration becomes a conflict prevention method as a way of identities conflicts control proactive effect on the conflict environment by means of structural change and rationalization of value controversies. Social and cultural integration implies equitable social relationships, civic solidarity, moral community, based on tolerance, tactfulness, trust and security.

The systemic crisis caused by lingering identities conflicts at the regional level can be overcome by purposefully constructing the integration civic identity, by cultivating such paramount elements of civic culture as democratization, pluralism, rationalized perception of "other" cultural identities. In the North Caucasian socium, the strategy of conflict resolution has to be built on the principles of civic solidarity and cooperation but not on assimilation policy or suppression of ethnic distinctions. 


\section{Acknowledgments}

The paper has been prepared within the project "Social and cultural integration as a way of reducing the ethnic tension in the North Caucasus", President's grant MD-7429.2015.6.

\section{References}

Avksentiev, V.A., Shul'ga, M.M. (2013). Stavropolie mnogonatsional'noe: oplot stabil'nosti ili perekrestok problem? [The multinational Stavropol territory: a stronghold of stability or a crossroads of problems?]. Sotsiologhicheskie iss/edovaniya, No. 12, 3, 34-42.

Burton, J. (1990). Conflict: Resolution and Prevention. London: Macmillan and New York: St. Martin's Press.

Rothman, J. (1997). Resolving Identity-Based Conflict: In Nations, Organizations, and Communities. San Francisco: Jossey-Bass Publishers.

Rothman, J., Alberstein, M. (2013). Individuals, groups and intergroups: Understanding the role of identity in conflict and its creative engagement. Ohio State Journal on Dispute Resolution, №28 (3), 3, 631-658. 